Int. J. Electrochem. Sci., 11 (2016) $8082-8095$

\title{
Application of Stabilized Monodisperse Antimicrobial Silver Nanoparticles Produced from x- ray and Photographic Films as Corrosion Inhibitor for Carbon Steel in Aqueous Acidic Solution
}

\author{
Ayman M. Atta ${ }^{1,2, *}$, Gamal A. El-Mahdy ${ }^{1,3}$, Hamad A. Al-Hodan ${ }^{1}$, Abdelrahman O. Ezzat ${ }^{1}$ \\ ${ }^{1}$ Surfactants research chair, Chemistry department, college of science, King Saud University, Riyadh \\ 11451, Saudi Arabia. \\ ${ }^{2}$ Petroleum Application Department, Egyptian Petroleum Research Institute, Nasr City 11727, Cairo, \\ Egypt. \\ ${ }^{3}$ Chemistry department, Faculty of science, Helwan university, Helwan, Egypt. \\ *E-mail: aatta@ksu.edu.sa
}

doi: $10.20964 / 2016.09 .32$

Received: 15 June 2016 / Accepted: 16 July 2016 / Published: 7 August 2016

\begin{abstract}
New antimicrobial silver nanoparticles (Ag NPs) can be synthesized using recycled X-ray and photographic films by green, simple, easy, cost effective and environment-friendly chemical method. It is based on stripping both $\mathrm{Ag}^{+}$ions and gelatin layer of recycled films followed by reducing silver ions in an aqueous media in the absence and presence of glucose and poly(vinylpyrrolidone), PVP, as reducing and stabilizing agents. In this study, gelatin acts as a reducing and stabilizing agent for the first time. The optimum conditions such as stripping time, temperature, gelatin and PVP concentrations, crystalline structure, particle distribution and size of Ag NPs was investigated. Ultraviolet - visible spectra was used to study the chemical stability of Ag NPs in $1 \mathrm{M} \mathrm{HCl}$ to be applied as a thin antimicrobial layer to protect the steel surface from corrosion.
\end{abstract}

Keywords: silver nanoparticles; antimicrobial; green chemistry; electrochemical; x-ray medical films.

\section{FULL TEXT}

(C) 2016 The Authors. Published by ESG (www.electrochemsci.org). This article is an open access article distributed under the terms and conditions of the Creative Commons Attribution license (http://creativecommons.org/licenses/by/4.0/). 